\title{
Assessment of Oral Feeding Readiness Among Preterm Infants
}

\author{
Atiat Ahmed Osman, Eman Sayed Ahmed, Farouk El Sayed Hassanein, Hend Sayed Mohamed \& Debra \\ Brandon
}

Assistant Lecturer, Department of Pediatric Nursing, Faculty of Nursing, South Valley University, Egypt. Professor of Pediatric Nursing, Faculty of Nursing, Assiut University, Egypt.

Professor of Pediatrics, Faculty of Medicine, Assuit University, Egypt.

Lecturer, Department of Pediatric Nursing, Assiut University, Egypt.

Associate Professor, Director PhD and Postdoctoral Programs, Duke University School of Nursing, USA.

\begin{abstract}
Background: Being born preterm presents numerous challenges for the preterm infant including neurodevelopmental immaturity, physiologic instability, and behavioral state disorganization. In this context, there are often challenges with the initiation and achievement of full oral feedings. Recognition and support of oral feeding readiness may accelerate feeding progression period and decrease length of hospital stay (LOS), thereby reducing healthcare costs. Supporting effective cue-based oral feeding through use of rigorous assessment or evidence-based care guidelines can optimize the hospital experience for infants and caregivers. Aims: This study aimed to assess premature infant's readiness level at the beginning of oral feeding. Identify factors that contributed to readiness in premature infants. Methods: A descriptive cross sectional design used in this study. Subjects: A convenience sample of 75 stable premature infants recruited from five neonatal intensive care units (NICUs) in Assuit city, Egypt. Infants' gestational age ranged from 30 to $\leq 32$ weeks post menstrual age (PMA). Tools: Infant's readiness assessed directly after oral feeding was introduced by using Neonatal Oral Motor Assessment scale (NOMAS). Results: Majority of the premature infants showed feeding readiness behavior (74.7\%) when they received their first oral feeding. No relationship between infants' gestational age at birth or weight and readiness behavior was observed. Conclusion: Most of infants had high level of readiness when oral feeding was initiated, correlation between infant's characteristics and readiness level were not significant. Recommendations: Encourage clinician to use standard measure as NOMAS to early assess readiness behavior of premature infants. And address NOMAS as a routine process in NICUs.
\end{abstract}

\section{Key words: Preterm Infants, Oral Feeding, Readiness \& NOMAS.}

\section{Introduction}

Feeding preterm infants is a skilled nursing task which requires assessing how and when to feed the preterm infant (Kish, 2013). Introduction of oral feeding in premature infants can be a challenge and there are no well-established evidence based standards to guide the initiation leaving decisionmaking to individual preferences and local customs (McClur, 2013). However, there are some accepted oral feeding practices for premature infants such as not feed in the first weeks of life for extremely preterm infants and not when orally intubated (Gennattasio et al., 2015), In addition, infant characteristics and clinical behaviors specific to feeding have been found to be more important than post menstrual age when assessing feeding abilities in premature infants (Belfort et at., 2011), Infant feeding by its nature is an interactive, developmental task (Thoyre et al., 2016).

Research indicates that feeding readiness behavior should be used to determine the timing and frequency of feeding during the day regardless of when oral feeding was initiated (Welma, 2017), Traditionally, measuring a preterm infant's readiness for oral feeding was derived from the required intake volume, regardless of an infant's readiness behaviors. Too often an infant's skills were overshadowed by the pressure to "get" the infant to eat, theoretically facilitating transition to discharge. In this context, preterm infants were pushed to be orally fed before they were physiologically or behaviorally ready resulting in longer feeding progression, hospitalization and more stress for the infant (Morgan, 2014), Preterm infant feeding ability is also closely related to the caregiver's ability to understand and distinguish physiological and behavioral readiness signs and caregivers' subsequent responses (Pickler et al., 2009).

Assessment of feeding readiness is essential to minimize the stress of feeding and facilitate the acquisition of full oral feedings. Therefore, neonatal oral motor assessment scale (NOMAS) which originally developed by (Palmer, 1993), a frequently used visual observation method to assess the nutritive 
sucking (NS) and nonnutritive sucking (NNS) skills of infants up to the age of 8 weeks post term. The NOMAS has the flexibility to be used during breastfeeding as well as bottle-feeding (Palmer, 1993, Palmer et al., 1993), So, aim of this study was to assess infant oral readiness level at the introduction of oral feedings through using of NOMAS. In addition, identify factors that contribute to readiness among premature infants.

\section{Significant of the study}

Nipple feeding represents one of the greatest challenges for both preterm infants and their caregivers, due to the mechanics required and potential dangers of initiating oral feeding before an infant is ready. It is important to carefully observe and assess infant readiness behavior in order to enhance effectivity and effectiveness to preserve energy for growth and avoid aspiration.

\section{Aims of the study}

This study aimed to assess premature infant's readiness level at the beginning of oral feeding. Identify factors that contributed to readiness in premature infants.

\section{Research questions}

- What are readiness levels of premature infants at the beginning of oral feeding?

- What are indicators of readiness among premature infants?

\section{Subjects \& methods}

\section{a. Design}

A descriptive cross sectional observational design was used to determine the feeding readiness level in premature infants when oral feedings were introduced. The study was approved by Duke Medicine Institutional Review Board, Duke University, North Carolina, USA; also, approved by Research and Ethical Committee at Faculty of Nursing, Assuit University, Egypt ${ }^{(1)}$. Permission was also received from the directors of the study hospitals after reviewing of the study proposal.

\section{b. Sample \& Setting}

A convenience sample of seventy-five clinically stable preterm infants born at 30 to $\leq 32$ weeks gestation were included in this study. They recruited from the available five NICUs in Assuit city (Assuit University Children, Gynecology\& Obstetrics\& Children, Assuit General, El-Eman, and El-Mabara hospitals), Egypt ${ }^{1}$. Infant's gestational age were determined by the attending neonatologist in NICUs. Infants who have congenital anomalies or who were medically unstable were excluded.

\section{c. Tools}

Two tools used to collect data of this study

Tool (1): Demographic and infants' characteristics: Included medical records to describe the infants, hospital number, date of admission, gender, date of birth, gestational age, vital signs, and weight at birth.

Tool (2): Neonatal oral motor assessment scale (NOMAS): The NOMAS is used to evaluate readiness for oral feeding in premature infant. The NOMAS was originally published by Braun and Palmer (Braun \& Palmer 1985), The revised version of the NOMAS (Palmer, 1993), was used to evaluate readiness for oral feeding in premature infant within 24 hours from the beginning of oral feeding. The NOMAS is a flexible scale that can be used to assess either bottle feeding or breastfeeding in both preterm and full-term infants (Howe et al., 2008), The scale has adequate psychometric properties including; test retest reliability (0.67-0.82) (Braun \& Palmer 1985), interrater reliability (0.930.97) (Case-Smith, 1988); and acceptable internal consistency (Howe et al., 2007), Construct validity was supported by several authors (Braun \& Palmer 1985; Case-Smith et al., 1989, Howe et al., 2007) while predictive validity was confirmed in one study (Palmer \& Heyman 1999), The NOMAS has more stability and consistency than other readiness measurements (Bingham et al., 2012),

The NOMAS contains four major categories of normal and abnormal characteristics of jaw and tongue movements. Infant's tongue and jaw behaviors are identified and quantified during a 1 min trial of nonnutritive sucking and through a 2 minute trial of nutritive sucking (Braun \& Palmer 1985). The original NOMAS didn't have scoring system, so, the Gaebler and Hanzlik scoring system (Gaebler \& Hanzlik 1996) used in this study, normal characteristics for each item were scored as $0=$ not at all, $1=$ brief $4-10 \%, 2=11-50 \%, 3=51-100 \%$ of the total time, while abnormal characteristics were scored as $1=$ absent, $0=$ present. Scale development did not include a cutoff point or total score calculation for readiness (Braun \& Palmer 1985; Palmer et al., 1993), the total score was obtained by summing the score of normal and abnormal characteristics categories, with a higher scale score representing greater readiness (mean of readiness total score used to classify preterm infant to ready and not ready; below mean called not ready and above mean called ready). Infants were video recorded once immediately before their first oral feeding.

\section{d. Procedure}

A pilot study was completed with 10 infants to test the applicability and feasibility of the intervention

(1)The original study was conducted with co-supervision with Duke University, School of Nursing, USA and Faculty of Nursing, Assuit University, Egypt. The study approval and data collection were done in Egypt, and then approved from IRB committee at School of Nursing, Duke Universitv. North Carolina. USA. 
and tool (NOMAS). High internal consistency was identified through a pilot study $(0.937$ by Cronbach's alpha test). Once oral feeding was initiated, feeding readiness was assessed using the NOMAS. A checklist assessed the infant's readiness behavior during NNS and NS. The researcher assessed the preterm during the 1 minute of NNS using a thumb and then during 2-minutes of nutritive sucking (NS) with a bottle feeding for immediate scoring on a checklist. Video recorded was done twice to each infant through NS or NNS at the beginning of oral feeding to be reevaluated by the researcher to confirm the NOMAS score.

\section{e. Limitations}

Several limitations of this study; firstly, our study focused on infant itself without attention to family.
Assessment of readiness for oral feeding was limited to when the decision to initiate oral feeding made. Therefore, the time when an infant was ready for oral feeding is not known.

\section{f. Statistical analysis}

Descriptive statistics were used to describe the sample using Mean and SD. Non-directional statistical tests were performed with the level of significance set at 0.05 for all tests due to the exploratory nature of this secondary analysis. Spearman or Spearman point-by serial correlational analyses were conducted to examine the relationship between the infant characteristics and NOMAS oral readiness total scores. Non-parametric methods were applied due to non-normality of data distributions and the small sample size.

\section{Results}

Table (1): Premature Infant's Characteristics.

\begin{tabular}{|l|c|}
\hline \multicolumn{1}{|c|}{ Variables } & Total Sample N=75 \\
\hline Gestational age at birth, $\boldsymbol{n}(\boldsymbol{\%})$ & $30(40.0)$ \\
\hline 30 weeks & $8(10.7)$ \\
\hline 31 weeks & $37(49.3)$ \\
\hline 32 weeks & $1.5 \pm 0.2$ \\
\hline Birth weight, kg & $1.5(1.3,1.7)$ \\
\hline Mean \pm SD & $(1.1,2.1)$ \\
\hline Median $\left(25^{\text {th }}, 7^{\text {th }}\right)$ & $29(38.7)$ \\
\hline Min, Max & $46(61.3)$ \\
\hline Gender, $\boldsymbol{n}(\boldsymbol{\%})$ & \\
\hline Female & \\
\hline Male & \\
\hline
\end{tabular}

$S D=$ Standard Deviation; $25^{\text {th }}, 27^{\text {th }}=25^{\text {th }}, 27^{\text {th }}$ percentile;

Max, Min = Maximum, Minimum.

Table (2): Preterm infant's age at the beginning of oral feeding.

\begin{tabular}{|c|c|}
\hline \multicolumn{2}{|c|}{ Gestational age $(\mathbf{N}=75)$} \\
\hline Mean \pm SD & $31.6 \pm 0.0$ \\
\hline Median $\left(25^{\text {th }}, 75^{\text {th }}\right)$ & $31.0(30.5,32.4)$ \\
\hline Min, Max & $(30.2,33.4)$ \\
\hline
\end{tabular}

$S D=$ Standard Deviation $; 25^{\text {th }}, 27^{\text {th }}=25^{\text {th }}, 27^{\text {th }}$ percentile $;$ Max, Min $=$ Maximum, Minimum. 


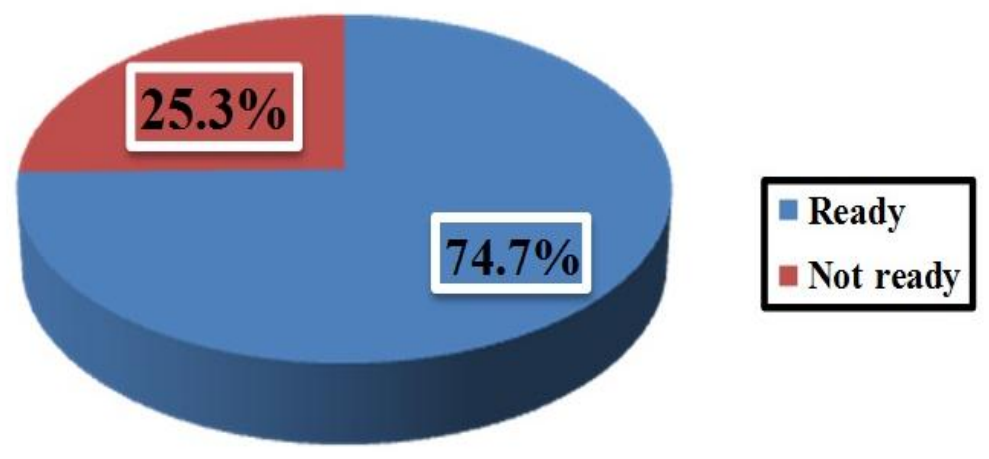

Figure (1): The distribution of preterm infants according to their readiness for oral feeding.

Table (3): Spearman Correlation between the preterm infant characteristics and their readiness for oral feeding.

\begin{tabular}{|l|c|c|c|c|c|}
\hline Infants' characteristics & Readiness & Gender & Wt., kg & GA, weeks \\
\hline Readiness & $\begin{array}{c}\text { Correlation } \\
\text { coefficient } \\
\text { P-value }\end{array}$ & 1.00000 & $\begin{array}{c}0.21068 \\
0.0696\end{array}$ & $\begin{array}{c}-0.04174 \\
0.7222\end{array}$ & $\begin{array}{c}-0.10517 \\
0.3692\end{array}$ \\
\hline Gender & $\begin{array}{c}\text { Correlation } \\
\text { coefficient } \\
\text { P-Value }\end{array}$ & $\begin{array}{c}0.21068 \\
0.0696\end{array}$ & 1.00000 & $\begin{array}{c}0.28754 \\
0.0124\end{array}$ & $\begin{array}{c}-0.25345 \\
0.0282\end{array}$ \\
\hline Wt., kg & $\begin{array}{c}\text { Correlation } \\
\text { coefficient } \\
\text { P-Value }\end{array}$ & $\begin{array}{c}-0.04174 \\
0.7222\end{array}$ & $\begin{array}{c}-0.28754 \\
0.0124\end{array}$ & 1.00000 & 0.36623 \\
\hline GA, weeks & $\begin{array}{c}\text { Correlation } \\
\text { coefficient } \\
\text { P-Value }\end{array}$ & $\begin{array}{c}-0.10517 \\
0.3692\end{array}$ & $\begin{array}{c}-0.25345 \\
0.0282\end{array}$ & $\begin{array}{c}0.36623 \\
0.0012\end{array}$ & 1.000000 \\
\hline
\end{tabular}

Spearman or Spearman Point-biserial Correlation Test for readiness; two tailed test results with significance set at $P \leq 0.05 ; G A=$ gestational age at birth; $B W=$ birth weight.

Infants' characteristics Table (1): Includes the characteristics of infants involved in this study, about half $(49.3 \%)$ of the included preterm infant had 32 weeks of gestation age. Mean and SD of birth weight for total sample were $1.5 \pm 0.2$. in addition, almost of preterm infants were male (61.3).

Table (2): Represents infant's gestational age (GA) at the beginning of oral feeding, Mean and SD of the total sample regarding GA was $31.6 \pm 0.0$ weeks. High percent of the preterm infants $(74.7 \%)$ were ready for oral feeding when the first oral feeding was introduced (Figure 1).

Table (3): Shows that there were no significant relations between infants' characteristics (gestational age, birth weight and gender) and feeding readiness level $(\mathrm{P}=0.3692,0.7222$ respectively $)$, however gender approached significance level $(\mathrm{P}=0.0696)$.

\section{Discussion}

This study found that, almost three quarters of the studied infants possessed feeding readiness skills at the time of their first oral feeding, with total GA around 32 weeks. Suggesting that Egyptian physicians introduced oral feeding at an appropriate time. However, these infants may have demonstrated feeding readiness before this time, because readiness was only assessed once before the first oral feeding. In this context, decision of oral feeding might be late. Although there are big debates regarding the appropriate time to introduce oral feeding in premature infants, caregivers vary in their opinion about feeding readiness. Some providers determine feeding readiness based upon infants' characteristics such as PMA (34 weeks) or weight (Younesian et al., 2015). In contrast, in the current study, physicians start oral feeding early among studied infants (before 34 weeks) with gestational close to 32 weeks. Furthermore, evidences concluded that starting oral 
feeding early can contribute to early attainment of full oral feeding and discharge in premature infants (Asadollahpour, et al., 2015) and could enhance early infant mother interaction and early breast feeding through early discharge (Pickler et al., 2009). Opportunity to develop suck-swallow and breathing sequencing through more frequent bottlefeeding, that allow them to increase nipple efficient experience (Drenckpohl et al., 2009). Similarly, we found that introduction of oral feeding could occur as early as 31 weeks PMA leading to accelerated transition time from tube to full oral feeding. Or even youngers as early as 30 weeks PMA (Fucile et al., 2012) Simpson et al., (2002) found that preterm infants who had early initiation of bottle feeding achieved total oral feeding significantly faster than controls.

During period of data collection, the researcher observed that the management of oral feedings was left to the discretion of the attending physician not the researcher, including the order of introducing oral feeding for premature infants. Based on the researcher observation, there are general guidelines for the management of oral feedings, however there is no specific protocol or tool to determine initiating and advancing oral feedings at the participating institution. They depend on general indicators such as: the residual for the last feed, sucking (tested by examiner finger), respiratory rate, current weight, weight gain, and PMA. Even, new researches refer to importance of readiness behavior as indicator to introduce oral feeding more than infants' weight or PMA (Pickler et al., 2009), In this context, infants' characteristics, such as, weight and gestational age did not predict readiness for oral feeding in premature infants in our study. Therefore, more attention should be direct to assess infant readiness clues such as, alertness, rooting, interest and competence in nonnutritive sucking, and good muscle tone (Lau, 2016, Neto et al., 2016). These studies provide support that infants' weight does not separately predict readiness for oral feeding (Holloway, 2014, Park et al., 2015).

Through preterm infants, these readiness behaviors may occur at short, irregular intervals and be subtle and fleeting considering their sleep for long time. Therefore, the nurses must be watchful for them through their short arousal opportunity before the infant returns to sleep. Should these readiness indicators be absent, the caregiver is directed to defer the bottle-feeding until they are present and to accomplish the feeding by slow gavage. So, it's extremely important to continuously assess the readiness cues (Peters, 2011).

\section{Conclusion}

Most infants were ready when oral feeding was initiated, while infant's characteristics such as infants' weight or gestational age could not predict readiness status among preterm infants.

\section{Recommendations}

It's recommend increase introduce oral feeding for premature infants early as the infants showed readiness signs at small gestational age (32 weeks). Health care giver need to focus on the clinical assessment to determine readiness level among premature infants instead of infants' characteristics. NICUs directors need to consider the establishment of official guidelines to measure readiness level among preterm infants. Administer further study with big sample size to determine readiness predictors.

\section{Reference}

1. Asadollahpour, F., Yadegari, F., Soleimani, F., Khalesi, N., (2015): The Effects of NonNutritive Sucking and Pre-Feeding Oral Stimulation on Time to Achieve Independent Oral Feedingfor Preterm Infants. Iran J Pediatr, 25(3):e809. DOI: 10.5812/ijp.25(3)2015.809

2. Belfort, B., Rifas-Shiman, L., Thomas, S., Carmel T., Andrew J., Philip R., Ken P., Matthew, W., Robert, A., \& Makrides, M., (2011): Infant Growth Before and After Term: Effects on Neurodevelopment in Preterm Infants. Pediatrics journal, 128(4): 899-906. doi: 10.1542/peds.2011-0282

3. Bingham, P., Ashikaga, T., \& Abbasi, S., (2012): Relationship of Neonatal Oral Motor Assessment Scale to feeding performance of premature infants. Journal of Neonatal Nursing, 18(1), 30-36. Retrieved from doi:http://dx.doi.org/10.1016/j.jnn.2010.09.004

4. Braun, M., \& Palmer, M., (1985): A pilot study of oral-moto dysfunction in " at risk" infants. Physical \& Occupational Therapy in Pediatrics, 5(4), 13-25.

5. Case-Smith, J., (1988): An efficacy study of occupational therapy with high-risk neonates. American Journal of Occupational Therapy, 42(8), 499-506. Retrieved from http://ajot.aota.org/article.aspx? articleid=18815 21

6. Case-Smith, J., Cooper, P., \& Scala, V., (1989): Feeding efficiency of premature neonates. American Journal of Occupational Therapy, 43(4), 245-250. Retrieved from http://ajot.aota.org/article.aspx?articleid $=18800$ 92 
7. Drenckpohl, D., Dudas, R., Justice, S., McConnell, C., \& Macwan, K. (2009): Outcomes From an Oral Feeding Protocol Implemented in the NICU. ICAN: Infant, Child, \& Adolescent Nutrition, 1(1), 6-10. doi:10.1177/1941406408328535

8. Fucile, S., McFarland, D., Gisel, E., \& Lau, C., (2012): Oral and nonoral sensorimotor interventions facilitate suck-swallow-respiration functions and their coordination in preterm infants. Early Hum Dev, 88(6), 345-350. doi:10.1016/j.earlhumdev.2011.09.007

9. Gaebler, C., \& Hanzlik, J., (1996): The effects of a prefeeding stimulation program on preterm infants. Am J Occup Ther, 50(3), 184-192. Retrieved from http://ajot.aota.org/data/journals/ajot/930011/18 4.pdf

10. Gennattasio, A., Perri, E., Baranek, D., \& Rohan, A., (2015): Oral feeding readiness assessment in premature infants. $M C N$ : American Journal of Maternal Child Nursing, 40(2), 96-104; e109-110. doi:10.1097/nmc.0000000000000115

11. Holloway, E., (2014): The Dynamic Process of Assessing Infant Feeding Readiness. Newborn and Infant Nursing Reviews, 14(3), 119-123. doi:https://doi.org/10.1053/j.nainr.2014.06.006

12. Howe, T., Lin, K., F., C., Su, C., \& Hsieh, C., (2008): A review of psychometric properties of feeding assessment tools used in neonates. Journal of Obstetric, Gynecologic, and Neonatal Nursing, 37(3), 338-349. doi:10.1111/j.1552-6909.2008.00240.x

13. Howe, T., Sheu, C., Hinojosa, J., Lin, J., \& Holzman, I., (2007): Multiple factors related to bottle-feeding performance in preterm infants. Nurs Res, 56(5), 307-311. doi:10.1097/01.NNR.0000289498.99542.dd

14. Kish M., (2013): Oral feeding readiness in preterm infants: a concept analysis. Journal of the National Association of Neonatal Nurses, 13(4):230-7.

15. Lau, C., (2016): Development of infant oral feeding skills: what do we know? Am J Clin Nutr, 103(2), 616s-621s. doi:10.3945/ajcn.115.109603

16. McClur, D., (2013): An Evidence-based Approach to Feeding the LatePreterm Infant. (Doctor of Nursing Practice), Seton Hall University, unpublished Dissertation.

17. Morgan, P., (2014): Cue-Based Feeding to Support Oral FeedingSuccess for Preterm Infants in a Neonatal Intensive Care Unit. Southern Illinois University Carbondale, unpublished thesis
18. Neto, F., Franca, A., \& Cruz, S., (2016): OC24 - An algorithm proposal to oral feeding in premature infants. Nurs Child Young People, 28(4), 72. doi:10.7748/ncyp.28.4.72.s55

19. Palmer, M., (1993): Identification and management of the transitional suck pattern in premature infants. Journal of Perinatal and Neonatal Nursing, 7(1), 66-75.

20. Palmer, M., Crawley, K., \& Blanco, I., (1993): Neonatal Oral-Motor Assessment scale: a reliability study. J Perinatol, 13(1), 28-35.

21. Palmer, M., \& Heyman, M., (1999): Developmental outcome for neonates with dysfunction and disorganized sucking patterns: Preliminary fi ndings Infant-Toddler Intervention: The Transdisciplinary Journal, 9, 299-308.

22. Park, J., Knafl, G., Thoyre, S., \& Brandon, D., (2015): Factors associated with feeding progression in extremely preterm infants. Nurs Res, 64(3), 159-167. doi:10.1097/nnr.0000000000000093

23. Peters, K., (2011): Association between autonomic and motoric systems in the preterm infant. Clinical Nursing Research, 10(1), 82-90.

24. Pickler, R., Best, A., \& Crosson, D., (2009): The effect of feeding experience on clinical outcomes in preterm infants. Journal of Perinatology, 29. doi:10.1038/jp.2008.140

25. Simpson, C., Schanler, R., \& Lau, C., (2002): Early introduction of oral feeding in preterm infants. Pediatr, 110. doi:10.1542/peds.110.3.517

26. Thoyre, S., Hubbard, C., Park, J., Pridham, K., \& McKechnie, A. (2016): Implementing Co-Regulated Feeding with Mothers of Preterm Infants. MCN Am J Matern Child Nurs, 41(4), 204-211. doi:10.1097/nmc.0000000000000245

27. Younesian, S., Yadegari, F., \& Soleimani, F., (2015): Impact of Oral Sensory Motor Stimulation on Feeding Performance, Length of Hospital Stay, and Weight Gain of Preterm Infants in NICU. Iranian Red Crescent Medical Journal, $\quad$ 17(7), e13515. doi:10.5812/ircmj.17(5)2015.13515

28. Welma, L., (2017): Clinicians guide for cue based transition to oral feeding in preterm infants: An easy to use clinical guide. Journal of evaluation in clinical practices, 1-9. DOI 10.1111/jep.12721 